\title{
TEOLOGIA FORMAL AFRICANA
}

\section{José Armando Vicente ${ }^{1}$}

RESUMO: Não obstante a experiência colonial de despersonalização e de invasão cultural, as culturas africanas preservaram a sua vitalidade. Esta vitalidade cultural é a base do povo africano, na sua luta pela plena libertação e pela construção de uma sociedade humana. É necessário, contudo, reconhecer a persistência da situação de dominação que é resultado do colonialismo. Esta situação de denominação existe também nas Igrejas. O modelo de organização importado do Ocidente é ainda proposto e aceite. Isto é particularmente verdade na teologia. A vida das Igrejas foi dominada por uma teologia elaborada de acordo com uma metodologia, uma visão do mundo e uma concepção da humanidade impregnadas de categorias ocidentais. Portanto, a teologia africana já fez sua aparição e ela está viva. Entre as diversas abordagens em teologia africana, citam-se: a) uma abordagem teológica que, reconhecendo os valores inerentes às religiões tradicionais, descobre aí uma preparação para o Evangelho; b) uma teologia crítica que nasce do contato com a Bíblia, da abertura às realidades africanas e do diálogo com as teologias não africanas; c) uma teologia negra que toma em consideração a experiência de opressão e a luta pela libertação e encontra a sua inspiração na fé bíblica, expressa na linguagem e nas categorias da África.

Palavras- Chave: Teologia. Formal. Africana.

SUMMARY: Despite the colonial experience of depersonalization and cultural invasion, African cultures still have their vitality. This actual cultural vitality is the basis of the African people in their struggle for full liberation and the construction of a more humane society. Nevertheless, we cannot forget the maintenance of the position of domination that results from colonialism. This model still also exists in a religious level. The organizational model imported from West is still proposed and accepted. This is particularly true in theology. The organization and practice of churches is dominated by a theology based in western values. The methodology, worldview and conception of humanity is imbued in Western categories. Meanwhile, an African theology has borned and it is growing. Among the different approaches in African theology, there is: a) a theological approach which, recognizing the values inherent in traditional religions, discovers there a preparation for Gospel; b) a critical theology that is born from contact with the Bible, from openness to African realities and from dialogue with non-African theologies; c) a black theology that takes into account the experience of oppression and the struggle for liberation and finds its inspiration in biblical faith, expressed in the language and categories of Africa.

\section{Keywords: Theology. Formal. African.}

\footnotetext{
${ }^{1}$ Doutor em Teologia Sistemática pela Faculdade Jesuíta de Filosofia e Teologia - Belo Horizonte - Brasil. Doutorando em Educação pela Universidade Internacional Iberoamericana - UNINI-MX. Linha de Pesquisa: Multiculturalidade, Interculturalidade em educação. Pós-graduando em Educação Bilíngui e Plurilíngui na PUC - MG (Pontifícia Universidade Católica de Minas Gerais. Graduado em Filosofia (1999), no Seminário Maior de Filosofia em Moçambique; graduado em Teologia (2005) no Instituto Santo Tomás de Aquino - Belo Horizonte - Brasil; — Pós-graduação Lato Sensu em Especialização para Formadores de Presbíteros (2010), no Instituto Santo Tomás de Aquino - Belo Horizonte - Brasil; Pósgraduação Lato Sensu em Especialização em Sociologia e Psicologia Social (2019), na Universidade Estácio de Sá; Mestre em Teologia Sistemática (2012) pela Faculdade Jesuíta de Filosofia e Teologia - Belo Horizonte - Brasil. Pesquisador nas seguintes áreas: Teologia das religiôes; Pluralismo religioso. Diálogo Inter-religioso; Teologia Africana; as religiões; Educação: Multiculturalismo e Interculturalidade; Bilíngüismo e Plurilínguismo, Multilinguismo. E-mail: josarvicente@yahoo.com.br.
} 


\section{INTRODUÇÃO}

Neste artigo abordaremos o conceito de "Teologia formal Africana" ou “Teologia burguesa africana". A teologia formal é uma teologia que se encontra nos documentos escritos, nas discussões formalizadas, nas obras de teólogos africanos. Não custa lembrar que ao lado da teologia formal africana, existe uma "teologia informal africana" ou uma "teologia não-burguesa" que é expressa nas tradições orais (mitos, cantos, provérbios) dos povos africanos. A teologia informal apareceu antes que a "teologia burguesa", isto é, antes dos teólogos africanos escrevessem suas primeiras reflexões.

Aliás, no Ocidente também a teologia informal é anterior à teologia formal. De fato, a maioria dos cristãos não possui nenhuma teologia válida ou "teologia burguesa". Quando se pensa na teologia ocidental, ocorrem nomes como Schillebeeckx, Küng, Barth, Rahner, Tillich, Bruno Forte, Jacques Dupuis,...; dificilmente se pensa nos milhões e milhões de pessoas, cujas experiências religiosas são para elas tão válidas e tão autênticas como são válidas e autênticas as experiências religiosas de Schillebeeckx, Küng, Barth, Rahner, Tillich, Bruno Forte, Jacques Dupuis. Nesse sentido, tem que se distinguir entre a teologia burguesa ou formal e teologia não-burguesa ou informal.

Este artigo, portanto, se limita a um trabalho formal ou burguês da teologia na África e exclui o valor teológico de experiência oral. Trata-se de uma teologia que se tornou a prerrogativa de alguns teólogos africanos; que se tornou escolar, sólida em seus conteúdos, mas também abstrata.

A motivação neste artigo é mostrar à comunidade de teólogos ocidentais que a teologia africana já fez sua aparição e ela está viva e que, portanto, a tarefa dos teólogos africanos consiste em criar uma teologia que brote do povo africano e que tenha relevância para ele. Acredita-se que a teologia africana deve ser compreendida no contexto da vida e da cultura africanas e do esforço criador dos povos de África para constituir um novo futuro, diverso do passado colonial e do presente neocolonial. A situação africana requer uma nova metodologia, diferente das teologias dominantes do Ocidente. A teologia africana deve rejeitar, por conseguinte, 
as idéias pré-fabricadas norte-atlântica, definindo-se ela própria em relação às lutas do povo na sua resistência às estruturas de dominação.

O método empregado é a revisão de literatura sobre, a teologia africana conforme realizada pelos seguintes autores: Setiloane, Bimwenyi-Kweshi, Senghor, Tempels, Mulago, Lufuluado, Nothomb, Kagame, Mushete, Mbiti, Ozakom...

\section{CONTEXTO DO SURGIMENTO}

A África foi evangelizada repetidas vezes: a primeira evangelização remonta aos primeiros cinco séculos da era cristã, quando o Evangelho foi difundido no Norte da África até a Etiópia. Porém, a cristandade norte-africana cedeu com a queda do Império Romano e diante do avanço do islã.

A segunda evangelização começa na época dos descobrimentos geográficos efetuada por Portugal e Espanha. No entanto, é somente na época moderno, propriamente a partir do século XIX, com a penetração europeia na África central e meridional, que a missão consegue constituir uma cristandade na África negra. A evangelização e/ou a missão havia sido conduzida, na época moderna, sob o patrocínio de uma "teologia da salus animarum", isto é, "teologia da conversação dos infiéis". Esta era uma teologia que defendia que os negros são apenas selvagens que devem ser convertidos; as almas dos negros devem ser arrancadas uma por uma da escravidão dos demônios. Era uma teologia que defendia que os negros não tinham Deus, nem filosofia, nem teologia.

De acordo com Hurbon (1988), os missionários cristãos rotularam negativamente a Religião Tradicional Africana (RTA); eles, deliberadamente, procuram destruir, ou pelo menos desestabilizar, a religião, a cultura e as tradições africanas. Os missionários cristãos queriam converter os africanos não somente ao cristianismo, mas também à cultura a que pertenciam tais credos; trabalharam sem descanso para a conversão deles. Numerosos padres, pastores e missionários só se referiam à RTA como "macaquice”, indigna de povo civilizado. Diz Opuku: “pregavam contra a crença nos espíritos, nas forças sobrenaturais e nos deuses, na 
feitiçaria, nos sacrifícios, nos rituais, nos tabus e na veneração dos antepassados" (OPUKU, 1988, p. 597).

Segundo Vicente (202I), os deuses (ou divindades, antepassados, espíritos) foram identificados, percebidos e classificados como demoníacos pelos cristãos ocidentais; foram selecionados e revestidos com "roupas", nomes ou atributos helênicos e cristãos. (onisciente, onipotente, onipresente e transcendente).

Afirma categoricamente Vicente

\begin{abstract}
Os cultos dos negros eram e são considerados "diabólicos”, momentos de gritaria e atentados à moral e aos bons costumes. As danças, as festas eram interditadas. Na mentalidade dos ocidentais, por trás dos sacrifícios, das oferendas, das comidas e banhos de ervas, enfim, por detrás de todas as "obrigações" havia um poder maligno e diabólico em ação. Moralmente, a veneração aos antepassados e aos espíritos foi considerada idolatria (VICENTE, 2021, p. 37.
\end{abstract}

Os ritos de iniciação de rapazes e moças eram inadmissíveis e, portanto, interditados. Os missionários julgavam-nos prática abominável e, por isso, tentaram fazer com que os africanos os abandonassem totalmente. Os lugares de sacrifícios foram considerados "moradas" de demônios. Sendo assim, os missionários católicos e os ocidentais pretendiam acabar com a RTA: procuravam quebrar garrafas, vasos, jogar fora pedras, cortar as árvores junto às quais se realizavam as práticas religiosas, enfim, pretendiam profanar tudo o que era usado para o culto.

Continua Vicente

$$
\begin{aligned}
& \text { Os "sacerdotes" e "sacerdotisas" eram vistos como "ministros do diabo". } \\
& \text { Com essa atitude, colocava-se em xeque a autoridade dos tradicionais } \\
& \text { chefes dos africanos. Além disso, com a introdução da medicina ocidental, } \\
& \text { os missionários atacavam os costumes dos africanos, procurando } \\
& \text { enfraquecer a posição dos médicos e dos curandeiros tradicionais } \\
& \text { (VICENTE, 2021, p 37). }
\end{aligned}
$$

Dessa forma, os africanos eram considerados "perdidos", por quem os missionários católicos e protestantes deviam olhar com compaixão. Pairava, portanto, junto a esses missionários, a preocupação de batizar os praticantes da RTA e de extirpar a RTA.

O cristianismo que chegou à África começou por desvalorizar os costumes e tradições dos povos africanos. Assim, despojados de sua linguagem, de sua cultura, os africanos não tinham mais existência original. Uma vez que o 
catolicismo e o protestantismo se apresentavam como religião da civilização, da "sociabilidade", os negros sentiam-se reduzidos a seres primitivos, supersticiosos, discípulos de Satanás. Rejeitar a própria cultura, os próprios costumes era a eles passado como honra e compromisso. Deviam imitar a civilização, a sociedade, a cultura, o estrangeiro, o burguês. Difundiu-se, com isso, a ideia de inferioridade da cultura africana. Os africanos foram induzidos a acreditar que a verdadeira civilização era a ocidental; que a verdadeira religião era o cristianismo; que as verdadeiras igrejas eram a católica e a protestante; que as verdadeiras línguas eram o inglês, o francês, o português; que ser civilizado era sinônimo de ser cristão, de falar as línguas mencionadas.

Era grande a preocupação de civilizar os africanos via catolicismo e protestantismo. A política missionária visava a europeização dos africanos, confirmando assim a ideia errônea de que eles não conheciam Deus. Tudo o que era da África foi percebido como primitivo, pagão, fetichista e infiel aos olhos da Europa. Edusa-Eyison assinala:

A antiga atitude dos missionários mostrou-se, geralmente, destrutiva; a religião [africana] não era estudada, ela era considerada como não possuindo nenhuma revelação ou inspiração divina, e não se fez o mínimo esforço para utilizar uma sua qualquer parte como base de um ensinamento mais completo (EDUSA-EYISON, 2005, p. 99).

A missão cristã na África foi considerada um processo de "civilização". Os africanos eram considerados pagãos mergulhados nas trevas da ignorância, cujo caminho de vida era absolutamente primitivo e, por consequência, deviam ser evangelizados e/ou civilizados. Evangelizar, então, era sinônimo de civilizar ao modo ocidental. A missão visava a reprodução de um modelo único pelo qual as Igrejas africanas se tornavam um rascunho das Igrejas ocidentais. $\mathrm{Na}$ verdade, tratava-se de uma "teologia da Implantação da Igreja" (plantatio Ecclesiae"). A expressão não deve ser só entendida como uma simples transposição ou "transplantação" da Igreja europeia em África, mas realmente como uma semente plantada na África, sobre a tabula rasa da africanidade. 


\section{SURGIMENTO DA TEOLOGIA AFRICANA}

Pode-se então situar o nascimento da Teologia Africana nesse contexto da evangelização e/ou descobrimento da África na idade moderna. Trata-se de uma teologia que emerge no contexto sócio-político do povo africano e se propõe, portanto, em responder ao seu clamor conforme afirma o teólogo Júlio Zabatiero: "teologia se faz a partir do clamor, pois quem não consegue ouvir o clamor de quem sofre, também não consegue ouvir a palavra que Deus fala" (ZABATIERO, 200I, p. 16). De fato, foi em função do clamor do seu povo que os teólogos africanos se levantaram conscientes de suas responsabilidades enquanto intérpretes das suas tradições e propondo deste modo soluções aos problemas pontuais das suas comunidades. Evidentemente que, não se trata de uma tarefa simples, pois, pressupõe antes de qualquer coisa numa libertação cultural dos africanos e na recuperação da sua africanidade, na visão de vida, cultura, sabedoria e religiosidade. A teologia africana busca libertar e situar o africano no seu contexto e consequentemente levar o mesmo a apreender que ele é sujeito, que seus pensamentos são legítimos, que sua visão de mundo e de vida é legítima, que seus sentimentos são igualmente legítimos.

Portanto, a teologia informal começa a delinear-se num livro intitulado Des prêtresnoirss'interrrogent, de 1956. É uma coleção de artigo, assinado por alguns padres negros, que no meio do processo de descolonização se perguntavam sobre o futuro da missão da Igreja na África. Mais tarde, em 196o, na faculdade de teologia católica da universidade do Congo foi aberto um debate sobre a possibilidade de uma teologia africana. O debate iniciado pouco a pouco se ampliou: a mesma faculdade católica do Congo organizou um "Colóquio sobre a teologia africana" em 1968; e, no âmbito protestante, organizou-se, em 1966, um congresso para a África, com o tema "Por uma teologia africana". Com esses debates, começava um processo de esclarecimento teológico.

Percebe-se, então, que antes dos debates, diria Senghor que:

A alma negra, uma raça, quase um continente não teria pensado nada, nada sentido, nada pintado ou esculpido, nada cantado ou dançado. Um nada no fundo do abismo, capaz apenas de implorar e de receber: uma cera 
mole nas mãos do Deus branco de olhos azuis como o céu (SENGHOR, apud GIBELLINE, i998, p. 457).

Porém, por volta do século XX, surge o movimento cultural de Negritude que procurava a recuperação da identidade negra, a fidelidade à história africana, à solidariedade de todos os negros da África e da diáspora. O movimento de Negritude provocou um florescimento de estudos literários, artísticos e filosóficos tendentes à recuperação da cultura africana. Insiste Senghor: "Nossa libertação será mérito dos escritores e dos artistas africanos, mais que dos políticos. A experiência veio mostrar que sem a libertação cultural não existe libertação política" (SENGHOR, apud GIBELLINE, 1998, p. 457).

Nesse esforço literário, pode-se inserir a obra pioneira do missionário franciscano belga, Padre PlacideTempels, A filosofia banto, publicada em 1945. Nessa obra se descobria e se documentava a existência de uma "visão do mundo", de uma "filosofia especificamente africana". Essa obra permitiu enfocar nos anos 50 e 60 o problema de uma teologia africana.

De fato, a partir dos anos 6o, nas faculdades de teologia de Congo e em outros centros teológicos e em numerosos estudos delineava-se a proposta de uma "teologia da adaptação". O termo adaptação evoca um organismo vivo que procura ajustar-se a um contexto ambiental. Teologicamente, o termo exprime a exigência de encontrar pontos de inserção do anúncio cristão, em crenças, ritos, símbolos, gestos e instituições da sociedade africana tradicional, aparentemente, compatíveis com os dados da fé cristã, de modo a dar um rosto africano ao cristianismo. Na verdade, é uma tática externa de modificações para que o único modo eclesial possa ser aceito, revelando certa mentalidade de superioridade do cristianismo ocidental. Nesse processo de adaptação ou africanização deram sua contribuição Vicent Mulago, Placid Tempels, F. M. Lufuluado, D. Nothomb, Alexis Kagame. A “teologia da adaptação" era uma superação decisiva da concepção de uma teologia da tabula rasa da africanidade e representou a primeira e mais avançada forma de "teologia africana”, até o Concílio Vaticano II. A reflexão teológica posterior conseguiu superar a "teologia da adaptação", tida como concordista, em favor de uma "teologia 
da encarnação" ou "teologia da inculturação", isto é, de um processo segundo o qual a mensagem salvífica e a própria igreja deviam se encarnar na África.

\section{CARACTERÍSTICAS DA TEOLOGIA AFRICANA}

A priori, vale destacar que não existe uma uniformidade entre os autores quanto ao conceito de teologia africana. Oscar Bimwenyi simplesmente fala de teologia africana; o teólogo zairense Alphons Ngindu Mushete fala de "teologia africana crítica". Para John S. Mbiti a teologia africana seria simplesmente "reflexão e expressão teológica feita por cristãos africanos" (MBITI, apud HOUVLAND, 2015, p. 214). Por outro lado, Ambrose M. Moyo propôs uma definição mais singela, salientando que a teologia africana é "uma tentativa de traduzir a mensagem de Jesus por meio de formas de pensamento que a África achará relevantes e significativas"( MOYO, apud HOUVLAND, 2015, p. 214). Já Charles Nyamiti afirma que a teologia africana é a verdadeira e exata doutrina católica, expressa e apresentada de acordo com a mentalidade e as necessidades africanas. Para Gabriel M. Setiloane teologia africana é: "uma teologia que é baseada na fé bíblica e que fala à alma africana (...) Ela se expressa através das categorias de pensamento que provêm da filosofia e da visão de mundo dos africanos" (SETILOANE, 1992, p. 50). Nesse sentido, a teologia africana busca falar à alma africana, e essa linguagem se dá mediante a experiência subjetiva com o sagrado. Para Setiloane toda teologização é feita a partir do seu contexto, no entanto, a teologia que predomina nos seminários e igrejas na África tem sido na verdade Teologia Ocidental. Isto implica que o olhar do africano em relação as suas experiências e, sobretudo, a Divindade está sempre condicionado ao preconceito europeu. Implica igualmente que o africano tem convivido com dois mundos distintos: por um lado tem a sua visão de mundo tradicional e por outro o mundo da cultura ocidental.

No entanto, para além das diferenças linguísticas e das diversidades das abordagens, a teologia africana assumi características próprias. A priori, vale a pena deixar bem claro que a teologia africana não deve ser simplesmente 
caracterizada como uma crítica negativa da cultura e filosofia ocidentais, mas uma avaliação positiva de sua própria cultura e filosofia africana.

- A primeira característica da teologia africana diz respeito à questão cultural: uma cultura, que é profundamente marcada pela religião, que exerce influência maior nos africanos quando comparados a outros povos, e o método de pensamento é influenciado pela mesma.

- A segunda característica é a comunitária, com a proposta de uma eclesiologia africana, com bases teológicas intrinsecamente ligadas à ação cristã, da qual emerge e pela qual é explicável.

- A terceira característica é a ecumênica: uma teologia que é feita na e pela comunidade. Ela é ecumênica porque se estende a totalidade do mundo humano habitado, sem exclusão de pessoas ou de comunidades de fé diferentes. É uma teologia que fala da cultura de um povo, dos seus medos, das suas expectativas, dos seus sonhos, dos seus sofrimentos e, acima de tudo, propõe soluções aos problemas pontuais que o mesmo apresenta, pois, teologia não se faz apenas articulando discursos, mais sim buscando a materialização dos mesmos. Ela não acontece fora do ciclo cultural de um povo, antes pelo contrário é a resposta ao grito do povo, nesse sentido, o teólogo não é apenas pesquisador do conteúdo bíblico, mas também interprete do mesmo para a realidade de sua comunidade.

\section{RUMO A UMA TEOLOGIA AFRICANA CRÍTICA}

Diz Bimwenyi-Kweshi:

Desde que a boa nova de Jesus Cristo ressoou nas florestas e savanas, e desde que muitos foram tocados, envolvidos ou perturbados no mais profundo de si mesmos por essa mensagem, uma das questões frequentemente levantadas diz respeito, precisamente, à compreensão dessa mensagem, de seu autor, das circunstâncias de sua transmissão e, finalmente, das consequências que a adesão a esse novo caminho leva consigo tanto no plano socioeconômico, sócio-político, como no plano cultural e religioso (BIMWENYI-KWESHI, apud GIBELLINI, 1998, p. 460).

Com essas palavras, tem início a vasta e imponente pesquisa a respeito

dos fundamentos de uma teologia africana; de uma elaboração teológica africana 
especificamente caracterizada; uma teologia crítica. Não se trata de recriminar as missões, e sim de revisitar o cristianismo "em situação colonial”, para discernir agora, as condições de "um encontro mais profundo e criativo entre Jesus e o homem religioso africano, e de um novo modo de ser Igreja na África negra. Acredita-se que o Evangelho é civilizador, mas não no sentido de ser o veículo da "civilização ocidental", e sim no sentido de que, lá onde ele é recebido, faz surgir uma nova civilização e uma nova cultura. A teologia na África, agora, deve ir decididamente além do discurso cristão "em situação colonial” em direção a um autêntico "discurso teológico negro-africano".

Conscientes, portanto, desta exigência teológica, os teólogos africanos Bimwenyi, entre outros, têm uma dupla e nobre missão. Eles propõem "libertar a Cristo e o Evangelho do cristianismo" colonial. Isso não quer significar a rejeição da pessoa de Jesus Cristo e do seu Evangelho. Realmente, a encarnação de Jesus Cristo e as outras afirmações a respeito de sua humanidade são aceitas pelos africanos. Para estes, Jesus Cristo não representa somente o Verbo de Deus que se fez carne, mas também o Filho de Deus feito Homem. Na opinião de Mustete, Jesus Cristo representa a humanização, ou seja, a humanificação (MUSHETE, 1988,p. 85). Por sua vez, Setiloane afirma:

\begin{abstract}
A felicidade com que aderiram ao Cristianismo prova que os africanos não encontraram nenhuma dificuldade em seu ensinamento básico a respeito de seu sujeito e mentor Jesus de Nazaré, nascido de maneira milagrosa de Maria, e outras afirmações fundamentais a respeito de sua humanidade. Para a visão do mundo africana tradicional também não houve motivo para questionar ou duvidar das afirmações sobre sua Divindade “concebido pelo Espírito Santo”, etc. Não tem sido difícil aceitar essas afirmações porque a nós não é estranha a ideia de a Divindade ser capaz de tomar "posse" de um ser humano .... como ... a entrada da Divindade para dentro da pessoa humana - a possessão, para levá-la a florescer em nível mais alto da sensibilidade e disponibilidade para os seus fins (SETILOANE, 1992, 53).
\end{abstract}

Pelo autor, percebe-se que a controvérsia diz respeito à universalização da tentativa limitada da Igreja Primitiva sobre a compreensão do mistério da ação da divindade. Como afirma Setiloane, "os Credos e as Doutrinas da Igreja, formulados pelos Primeiros Pais, estão envolvidos na mitologia e na visão da época em que foram formulados" (SETILOANE, 1992, p. 53). Sendo assim, algumas afirmações dos 
credos e da doutrina cristã ocidental não têm sentido na África. Os teólogos africanos querem denunciar e se libertar do Cristo e do seu Evangelho mergulhados na linguagem mítica e numa visão ocidental. Portanto, a luta não é contra a Fé ou o Kerygma, mas contra os acréscimos ocidentais transformados em dogma; contra o cristianismo acrescentado à civilização e à cultura ocidentais. A luta, na verdade, é contra as ataduras ocidentais, contra as ligaduras estranhas que escondem e aprisionam a Jesus Cristo:

Teologia africana significa para nós uma teologia que é baseada na fé bíblica e que fala à alma africana [...]. Ela se expressa através das categorias de pensamento que provêm da filosofia e da visão de mundo dos africanos. Falando pela África, o que não podemos comprar é a civilização ocidental, cultura, ou seja, que nome quiserem dar. Seus modelos de pensamento e formas de expressão Greco-romanas são as ataduras que precisamos de rasgar para chegar ao Cristo [...]. Se a verdade Teologia é reflexão, na Teologia Africana nós tentamos quebrar o selo dos modelos de pensamento e cultura ocidentais para podermos ver o Cristo face a face, $e$ nele vermos a nós mesmos [...] e a outros (DECLARAÇÃO DA AACC, apud SETILOANE, 1992, pp. 52-53).

A controvérsia, ou objeção, diz respeito ao Jesus Cristo e ao cristianismo

pregados pelos missionários e ensinados pelas igrejas nas escolas das missões, impostos pela disciplina das igrejas na vida quotidiana dos convertidos, conformados e moldados pela civilização ocidental a partir de ponto de vista e das atitudes dos missionários:

A verbalização ou interpretação da experiência da Divindade [e de Jesus Cristo] e dos assuntos que lhe dizem respeito em toda a vida, e morte, tem sido feita por pessoas ocidentais, através dos tempos. Na verdade, no centro de tudo isso tem estado o "fato", o "fenômeno", ou "acontecimento" de Jesus Cristo. Mas esse fato, fenômeno ou acontecimento tem também sido inevitavelmente compreendido e interpretado de um modo tendencioso. A tendência tem sido a situação ocidental, cultural, social e política, que tem ultrapassado os limites, através dos tempos (SETILOANE, I992, p. 49).

Por sua vez, escreve Chenu:

A teologia para nós, na África, não é um exercício escolar, com grande acompanhamento de palavras pretensiosas e de fórmulas enigmáticas. Para nós, a teologia pertence à totalidade de nossa experiência religiosa, à globalidade de nossa vida. Nos alegramos de sentir implicados na grande aventura da encarnação de Filho de Deus feito Filho do Homem. E cada dia se vai fazendo mais Filho do homem africano (CHENU, 1989, p. 149). 
Num segundo momento, os teólogos africanos procuram verbalizar Jesus Cristo e o cristianismo a partir da perspectiva do ambiente e da cultura africana. Propõem-se inculturar Jesus e seu Evangelho. Têm por ambição a missão de encarnar o enunciado do mistério de Cristo na África; pretendem revelar, a partir dos valores culturais e religiosos africanos, "outro aspecto" de Jesus, pois, como diz o evangelista Marcos, “[...] Ele se manifestou com outras aparências [...]” (Mc I6,I2). Diria Mana: "Já não se trata de um Cristo vindo de outra parte ou baixado de um céu estrangeiro, mas de Cristo revelado no coração próprio das demandas essenciais da África, de suas forças humanizadoras e de suas esperanças espirituais mais profundas" (MANA, 200o, p. 173). Por sua vez, diz Ozakom: "Dado que Ele se apresenta como enviado de Deus, os seus hospedeiros terão uma atenção especial aos gestos e às palavras da mensagem da nova religião e tentarão decifrá-las no horizonte da sua própria experiência espiritual” (OZAKOM, 2012, pp. 88-89). Portanto, o Evangelho e a figura de Jesus podem ser articulados a partir dos valores africanos socioculturais e religiosos.

A teologia africana pretende valorizar as categorias culturais, morais e religiosas da África. Como afirma Mana, “a aposta não consiste, portanto, somente em mudar de sociedade, mas também em mudar de cristianismo" (MANA, 20oo. p. 196) a partir do patrimônio cultural e religioso da África.

A mudança a que aqui se refere consiste em sair de uma teologia e de um cristianismo do Ocidente, com suas lógicas profundas, para construir uma teologia e um cristianismo a partir da visão cultural da África. Trata-se de um trabalho de reinvenção, de reimaginação, de reorientação e de refundação de um cristianismo novo no contexto da África. É uma teologia e um cristianismo ancorados nas riquezas espirituais africanas, renovados em seus projetos de ser e propostos como caminhos de vidas para todos os africanos. Assim, a teologia e o cristianismo africanos não serão mais importados, mas componentes incontornáveis da cultura africana. A teologia africana deve trazer doravante a marca da cultura africana. Em outras palavras, trata-se de uma teologia encarnada no contexto da 
África; uma teologia desocidentalizada; uma teologia autenticamente africana, isto é, traduzida em todas as dimensões da vida africana.

\section{CONSIDERAÇÕES FINAIS}

Diria Bimwenyi que tanto a "teologia da Salus animarum" como a “teologia da plantatio Ecclesiae”, mas também a "teologia da adaptação”, que sustenta a necessidade de uma "africanização" do cristianismo na África, são formas modernas de um discurso judaizante, que confunde a fé cristã com um produto préfabricado a ser exportado, instalado ou adaptado, e, como tais, são "teologias emaranhadas na própria armadilha" (BIMWENYI, apud GIBELLINI, I998, p. 46I). O problema é se e como é possível reencontrar um "lugar novo", donde partir para a elaboração de um discurso teológico africano, "sem passar pela sinagoga européia, pela circuncisão do espírito e do coração". De fato, a teologia africana deve passar pelo primado da linguagem e das concepções africanas. Assim, ela se enriquecerá de valores originais e únicos da África, que nem a língua semita, nem o espírito grego, nem o gênio latino lhe puderam trazer.

A teologia ocidental utilizou a metafísica grega para refletir a mensagem revelada. Uma teologia africana não deve passar necessariamente por essa mediação cultural. O teólogo africano que deseje tornar-se intérprete da fé de suas comunidades deve abandonar o "asilo epistemológico" de culturas e filosofias alheias. Trata-se de recuperar a africanidade, sua visão da vida, sua cultura, sua sabedoria e religiosidade.

A teológica africana crítica é apenas um começo; ela não elabora um discurso teológico africano acabado, mas apenas mostra a possibilidade e a legitimidade epistemológica de tal discurso. A teologia africana crítica se situa decididamente além da teologia da adaptação; mas ela tampouco se situa na teologia da encarnação ou da inculturação. Não é uma teologia previamente constituída e que se deve encarnar ou inculturar. Mas é uma teologia africana, um discurso teológico que deverá constituir-se na correlação de duas polaridades: a polaridade da revelação de Deus e a polaridade da africanidade. 


\section{REFERÊNCIAS BIBLIOGRÁFICAS}

BIMWENYI-KWESHI, Oscar, Discoursthéolgique negro-african, 1981: IN: GIBELLINI, Rosino. A teologia do Século XX. São Paulo: Loyola, 1998.

CHENU, Bruno. Teologías cristianas de los terceross mundos. Teologías latinoamericana, negra norteamericana, negra sudafricana, africana y asiática. Barcelona: Herder, I989.

DECLARAÇÃO DA AACC - Conferência das Igrejas de Toda a África - em sua Assembleia em Lusaka, I973: IN: SETIOANE, Gabriel. Teologia Africana: uma introdução. São Paulo: Faculdade de Teologia da Igreja Metodista, I992.

EYISON, Joseph M. Y. Edusa. Kwesi A. Dickson. Um biblista em busca de diálogo. In: Teologia Africana, Vol. II, Prior Velho: Paulinas, 2005.

GIBELLINI, Rosino. A teologia do Século XX. São Paulo: Loyola, 1998.

HOVlAND, Thor H. O Novo Paradigma da Teologia Africana. In: Teologia Africana, Vol. II, Prior Velho: Paulinas, 2005.

HURBON, Laënnec. O Deus da Resistência Negra. O Vodu Haitiano. São Paulo: Paulinas, 1988.

MANA, Ka. Teología Africana para tiemps de crises. Cristianismo y reconstrucción de África. Estela: Verbo divino, 2000.

MUSHETE, AlphoneNgindu. A figura de Jesus na Teologia Africana. Petrópolis: Vozes, 1988.

OPUKU, Kofi Asare. A religião na África durante a época colonial. In: História Geral da África, UNESCO, 1988. 
OZAKOM, Claude, Óscar Bimwenyi. O fim de um período de discussão sobre a possiblidade de uma Teologia Africana, In: Teologia Africana, Prior Velho: Paulinas, vol. I, 2012.

SENGHOR, LéopoldSédar, apu, GIBELLINI, Rosino. A teologia do Século XX. São Paulo: Loyola, 1998.

SETIOANE, Gabriel. Teologia Africana: uma introdução. São Paulo: Faculdade de Teologia da Igreja Metodista, 1992.

VICENTE, José Armando. A salvação na Religião Tradicional Africana. São Paulo: Loyola, 2021.

ZABATIERO, Júlio. Para uma teologia pública. São Paulo: Fonte Editorial; Vitória: Faculdade unida, 20or. 